\title{
Disclosing violence in calls for help
}

\author{
Emma Tennent and Ann Weatherall
}

\begin{abstract}
Violence against women is a pervasive problem, both in New Zealand society and around the world. Yet assessing the scale and effects of violence is difficult, as many women face barriers to disclosure. This paper examines women's disclosures of violence in calls for help to a victim support agency. We use conversation analysis and focus on membership categorisation to describe the different ways disclosures are built and understood in situ. It was only in a minority of cases (around 20\%), that callers made direct reference to violence, or categorised themselves explicitly as victims, albeit with indications of problems in speaking. However, for the majority, women did not mention the words 'victim' or 'violence' at all. Instead, culturally shared knowledge associated with categories of people (e.g. expartners) and places (e.g. home and jail) were used to build and interpret a description as a disclosure of violence. Our work contributes to an understanding of women's disclosures of violence by examining them directly in the setting where they occur. We discuss some of the insights gained from examining interactions in situ, and the practical applications of our work for improving services for women who have experienced violence.
\end{abstract}

Keywords: disclosures; domestic violence; feminist psychology; social interaction; gender and language; discourse

Affiliations:

Emma Tennent: Victoria University of Wellington, New Zealand. email: emma.tennent@vuw.ac.nz

Ann Weatherall: Victoria University of Wellington, New Zealand. email: ann.weatherall@vuw.ac.nz

\section{Introduction}

Violence against women is a pervasive problem in New Zealand society (Fanslow and Robinson 2011) and around the world. The immediate and long-term negative impacts on the health and well-being of women and their children have been well-documented (Devries et al. 2013). One important focus of social scientific research has been theoretical, asking how best to define violence and what causes it, in order to determine how best to reduce its occurrence (Lombard and McMillan 2012; Bender 2017). Another substantive line of investigation examines the criminal justice system and the ways laws and their enforcement treat victims poorly (Ehrlich 2001; Jordan 2015; Lees 2002). One unique contribution of feminist discursive research has been to show how broader cultural meaning systems about gender 
shape understandings and responses to violence and rape (Ehrlich 2014; Gavey 2005). The present paper contributes to feminist research on violence against women by examining how they disclose violence in their interactions with an institution who offers social support for victims of crime and trauma.

Numerous barriers have been documented that discourage women's disclosures of experiences of violence. Feminist post-structuralist critiques point to the minimisation and normalisation of violence (Gavey 2005) which means women may not consider themselves as victims (Lamb 1999). Interview studies suggest even those who recognise violence may not disclose due to feelings of shame, self-blame, or fear of violent reprisal (Jordan 2004; Keeling and Fisher 2015). Cultural conceptions of violence, (i.e. as a private family matter), can lead to an unwillingness to involve outsiders, particularly in contexts where family reputation is paramount (Othman, Goddard and Piterman 2014). Stigma associated with victimisation is one reason women give for enduring violence rather than disclosing it to others (Towns and Adams 2009). Women are more likely to confide in friends or family members than formal services, largely due to a lack of confidence in institutional responses (Jordan 2011). When reporting violence to police, women report a fear of disbelief and blame (Jordan 2004). In other institutional contexts like healthcare settings, hostile attitudes from service providers can bar women from mentioning violence, or contribute to its minimisation once raised (Keeling and Fisher 2015; Othman, Goddard and Piterman 2014).

Despite a wealth of research on the challenges women face in disclosing violence, scant research has examined how disclosures naturally occur in interactions with institutions, which is the focus of our study. Analysing disclosures as they occur can demonstrate how cultural understandings of gender and violence occur in practice. For example, Lindholm, Börjesson Cederborg (2014) examined police interviews where officers attempted to determine if women were victims of trafficking, or sex workers of their own volition. Through narrative analysis, the authors documented how discourses and moral hierarchies of victimhood were invoked by emphasising either responsibility or passivity. Cultural understandings and moral inferences are highly consequential matters for participants in such an environment where officers decide if women are victims or criminals.

Conversation analytic studies likewise examine naturally occurring interaction, with a focus on how disclosures are produced and used. This can demonstrate how common-sense understandings about gendered violence are used for particular ends in interaction. MacLeod (2016) analysed recordings of women reporting rape to police and found that women oriented to a need to account for their behaviour. Women frequently explained where they were and their relationship with the perpetrator, which MacLeod suggested pointed to the pervasiveness of rape myths. Women used accounts to pre-empt blame, and police officers treated this as an important part of the interview. The influence of rape mythology, in both police interviews (Jordan 2004) and courtrooms (Powell, Henry, Flynn and Henderson 2013) has long been critiqued by feminist scholars, but MacLeod's work is distinctive for documenting how this occurs in real interactions, which is something our work also does. 
Studies of naturalistic social interaction can also demonstrate how disclosures are responded to. For example, Ostermann (2003) compared responses to disclosures of violence in an allwomen police station and a feminist crisis intervention centre. She argued that different communities of practice (and their assumptions about victims and violence) shaped how institutional representatives responded to women's disclosures. Feminists tended to provide more affiliative responses after disclosures of domestic violence, such as aligning with women without evaluating their behaviour. Police officers' responses were more constrained due to the institutional focus on producing an incident report and assessing women's behaviour within a moral-criminal framework. Similarly, Greatbatch and Dingwall (1999) found that mediators side-lined disclosures of violence rather than pursuing the topic. Mediators tend to orient to the importance of impartiality over empathy (Stokoe 2003), which shows the relevance of interactional context to how disclosures are understood.

The research discussed so far shows that local environments organise how disclosures of violence are made and treated. It is clear that cultural beliefs about women and gendered violence have a pervasive influence on how disclosures of violence are made. Our own work analyses women's disclosures of violence in the institutional setting of a victim support service. Using conversation analysis, we examine how descriptions are built and interpreted as being about an experience of violence. In the context of our study those descriptions were used to secure the kind of emotional and practical support on offer. Category use has been established as the operation of culture-in-action (Hester and Eglin 1997). We found that the use of categories of people and places invoked the kinds of cultural commonsense that accomplished a joint understanding that a description was about gendered violence.

Our analytic approach draws on conversation analysis and membership categorisation analysis which shows how reference to people and places can be associated with particular activities and features. There is a fundamental link between categories and activities that means mentioning one can invoke the other (Sacks 1972; Fitzgerald and Housley 2015). An early, relevant research example by Wowk (1984) showed how a man accused of murder linked gendered categories and activities in a police interview to shift blame from himself to his victim. When the suspect described how his victim had propositioned him for sex, he invoked the category 'prostitute', without naming it directly. In doing so, he made moral inferences available about what kind of woman she was to work to avoid blame. This was a powerful demonstration of how people can use categories in talk to attribute blame and responsibility by leveraging common-sense cultural knowledge about what people are like and how they behave.

Categories can be grouped together through membership categorisation devices and in standardised relational pairs (Sacks 1972). Naming certain categories within a collection, or mentioning one member of a relational pair, can allow the listener to 'fill in the blanks'. An early example provided by Sacks (1995:113), in a similar context to our own, is a social agency calltaker who, upon hearing a caller's description of a family quarrel and a police call-out, challenges him, 'didn't you smack her one?' Sacks argued that the inference of violence is the result of shared cultural knowledge about reasons for police call-outs, and 
category-based expectations of people's behaviour. A key way the call-taker can make such inferences is through the relationship between categories. The categories of wife, sister and child mentioned by the caller could be grouped by the membership categorisation device 'family' (Sacks 1972). For the call-taker and, Sacks argued, all members of a shared culture, common-sense knowledge about police call-outs in the context of family members makes violence the 'missing piece' of the caller's story.

When multiple people are being categorised, as in the example above, the consistency rule means they can be heard as belonging together within the same device (Sacks 1972). Thus, in the above example, the wife, sister, and child are understood as members of the same family, rather than unrelated members of different collections. Category members within a device may form a standardised relational pair where each member has particular rights and obligations to the other (e.g. husband-wife) and can be associated with particular kinds of activities. Our analysis will show that the standard relational pair victim-perpetrator is key in the building and interpreting of a description as being about violence.

\section{Data and method}

In this study we analyse disclosures of violence in telephone calls to the New Zealand community organisation Victim Support. The organisation is closely affiliated with the criminal justice system and provides free services of support, advice and advocacy for victims of crime and trauma. Some support workers receive specialist training in sexual violence support, but in contrast to other non-governmental organisations in New Zealand like Rape Crisis or Women's Refuge, the organisation does not have a specific feminist focus on gendered violence.

The data used in this study are drawn from a larger corpus of 396 inbound calls to the victim helpline, recorded in 2015-16, including all inbound calls across a seven-day week in 2016. The phone line is managed by Victim Support's national Contact Service, which operates 24 hours a day, seven days a week. The corpus consists of 23 hours and 34 minutes of recordings. Over 80 per cent of calls were transferred, either to the organisation's volunteer support workers, or to other services like police or courts.

Callers were advised that calls were recorded for research and training purposes and could request the recording be stopped at any time. Contact service workers provided written consent to have their call recordings used for research, and were able to request any recordings be excluded from the sample. Sound files were edited to remove identifying information such as names, phone numbers and places. Transcripts produced following conversation analytic conventions (Jefferson 2004; Hepburn 2004) use pseudonyms to maintain confidentiality.

Each call collected for our research was listened to, given a unique identifying number, and catalogued with a brief description of the call contents and keywords. The data were indexed based on details like call length, gender of caller, reason for the call, incident type (if 
mentioned), and call outcome. From the incident type, reason for the call, and keywords, we identified 57 calls related to violence against women. Within the subset of calls about violence, 11 calls were made by a single caller across a week. Excluding her calls and other unclear cases, the final sample for this study is 39 calls clearly about domestic or intimate partner violence. Each call is Disclosing violence in calls for help 275 uniquely identified by the pseudonym of the contact service worker who answered the call and the call number.

\section{Analysis}

Our analysis examined how disclosures of violence were done and how a joint understanding was accomplished that the caller had experienced violence. In the majority of calls, the words 'violence' or 'victim' were never uttered. Using conversation analysis and drawing on work in membership categorisation analysis and its subsequent developments (Sacks 1972; Stokoe 2012a; Fitzgerald and Housley 2015), we document the kinds of commonsense knowledge associated with categories of person (e.g. ex-partner) and places (e.g. jail and home) that were used to build and interpret a caller's description of their experience as being about violence. However, we begin by showing a case from the minority of calls where there was an explicit reference to being a victim of violence.

\section{Explicit references to violence}

Some research has suggested that women may not disclose experiences of violence for a range of reasons including feelings of shame (Jordan 2004) or a lack of confidence in institutional responses (Jordan 2011). In around one fifth of our cases, callers did explicitly refer to violence. A recurrent place where that occurred was close to the beginning of the call, where a reason for contacting Victim Support was given.

The following extract provides one of the clearest examples of an explicit identification as a victim of domestic violence. It occurs in the caller's first turn of talk.

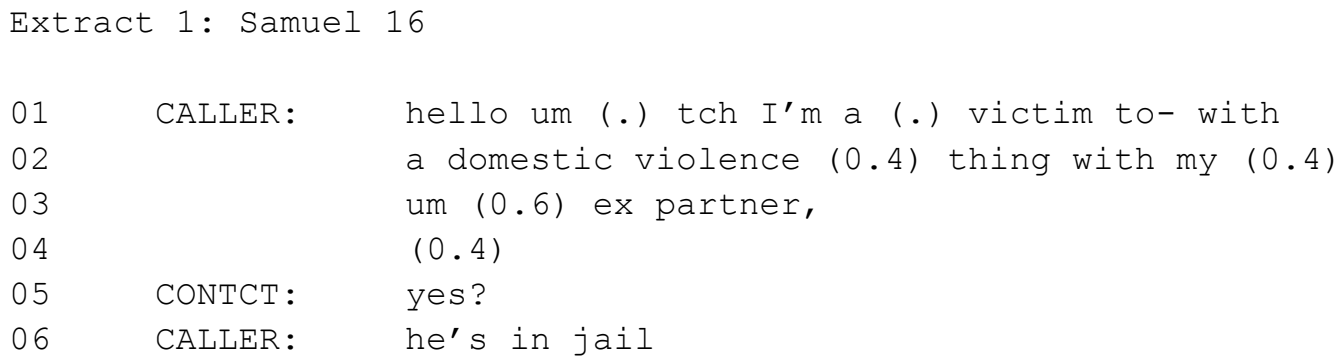

The 'um' in line 1 occurs in an interactional environment where it indicates a launching of the reason for the call (Schegloff 2010). In that slot, the caller identifies herself as a victim of domestic violence with her ex-partner (lines 1-3). The initial self-categorisation as a victim of a crime maps the caller into a category of people who are entitled to the support offered by the service - that is, victims of crime and trauma. 
Although the caller discloses they are a victim of violence immediately, the cluster of perturbations suggests there is some problem with doing so. There is a short silence after 'I'm a' and before 'victim' (line 1), which interrupts the smooth progressivity of the talk and functions as an alert to a possible trouble in word selection (Schegloff, Jefferson and Sacks 1977). Further evidence that it is a problem in formulation is the sound cut-off on 'to-' (line 1) which is another interruption in the smooth progressivity of the turn of talk in progress. That trouble is resolved by replacing the preposition 'to' with 'with' (line 1), which although grammatically wrong (of would be correct) is not observably oriented to as a trouble.

The caller also orients to her categorisation of 'domestic violence' as not being quite right because she adds, after another within-turn silence, 'thing' (line 2). The phrase 'domestic violence' is widely used by police and other organisations working within the violence sector. So the caller designs her reason for calling using terms fitted to the institutional setting. By adding 'thing' she indicates that that the description 'domestic violence' is not wholly adequate. There is a further silence and 'um' after 'my' (lines 2-3), which is another alert to a problem in speaking, this time in selecting a word to refer to the other party implicated in the incident. That trouble is resolved with the term 'ex-partner' (line 3).

In terms of membership categorisation 'victim' is strongly associated with 'perpetrator' because they are a standard relational pair (Sacks 1972). Without saying as much, the caller builds her description for a joint understanding of the ex-partner as the perpetrator of the violence. By referring to the incident as 'a domestic violence (0.4) thing' (line 2) the inference made available is that the perpetrator lives with and is known to the caller. This inference is modified with the reference term 'ex-partner' (line 3) which specifies that the relationship and co-habitation have ended. In fact, the perpetrator is now 'in jail' (line 6). Being in jail makes inferentially available that the ex-partner was arrested and charged for violence against the caller.

The above example shows an explicit self-categorisation as victim is a way of identifying as a relevant client for the service. Yet overwhelmingly callers disclosed experiences of violence (and thus identified as victims) without referring to this directly. In what follows, we show that violence does not need to be mentioned for it to be understood as the problem, but that person and place references on their own can be sufficient.

\section{Making inferences from person and place references}

Mentions of the location 'jail' made domestic violence relevant in the absence of explicit references to being a victim or a description of the violence. In the first cases presented below, the analysis describes how references to incarcerated ex-partners inferentially categorised them as perpetrators, and callers as victims of domestic violence. Home is another location that can be inferentially linked to domestic violence and later in this section, we show how common-sense knowledge about homes can also be used to build an understanding of domestic violence. 


\section{Ex-partners in jail}

In the following extract, the caller refers to an ex-partner in jail. Our analysis shows how the caller is describing domestic violence even though there are no direct mentions of it.

Extract 2: Ellie 4

01

CALLER: hi uhm: (0.2) I was just wondering if my ex

02 partner: (1.5) uh::m (0.7) is still in custody?

The ex-partner is categorised when the caller asks if he is 'still in custody' (line 2). People held in custody have (allegedly) committed a crime. In other words, being in custody is a place strongly associated to the category 'perpetrator'. A perpetrator is one member of a standardised relational pair. Following the rules of consistency and economy, if one member is categorised in one way, others should be too (Sacks 1972). If one (ex-)partner is the perpetrator, then the other (the caller) can be categorised as the victim, even though she does not explicitly identify herself in that way. That identification also classifies her as a legitimate service user entitled to support (evidenced in the following extract with an offer of transfer to the courthouse).

The categories 'victim' and 'perpetrator' can also be grouped using the larger categorisation device 'crime' which may include other membership categories like 'witness', 'police officer', 'lawyer' and so on. Crime is a categorisation device, like family, where the collection is duplicatively organised in a team-like unit with members of different categories having specific obligations to each other (Sacks 1995). Sacks importantly showed that when categories from within a duplicatively organised collection are listed, they are heard as part of the same unit. In the above extract, the common-sense understanding is that the caller is the victim of the crime her ex-partner committed, even though there is no direct mention of that. That the crime took place between people who can also be categorised as ex-partners, members of a (previous) family unit, means it was domestic or intimate partner violence.

The above analysis of how the common-sense understanding of violence is achieved is confirmed later in the same interaction when the caller describes how her ex-partner came to be imprisoned.

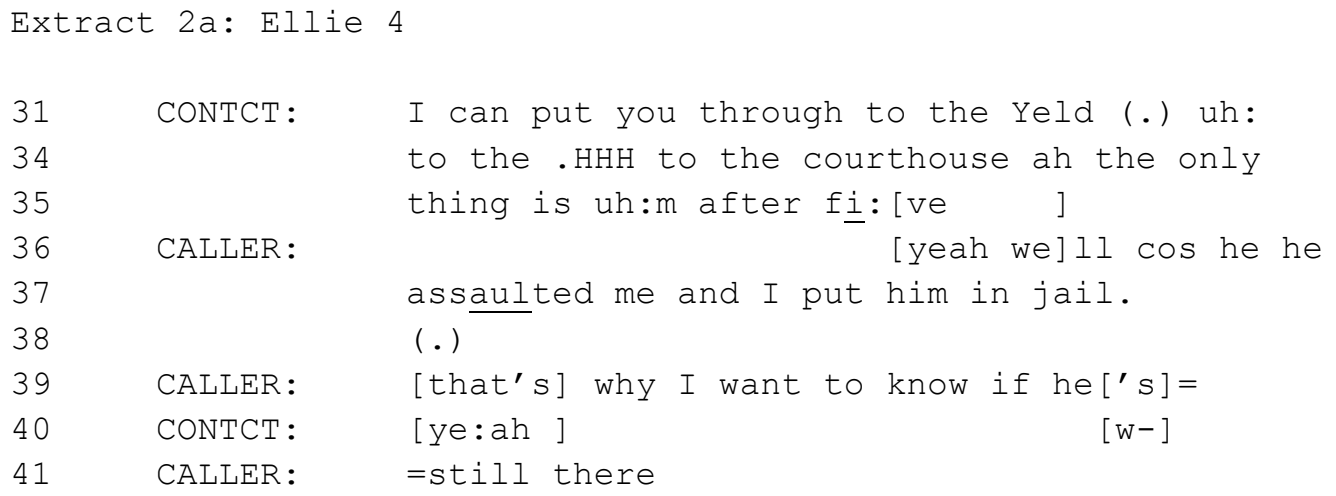


The inferences available from the caller's initial description are now explicitly referenced. The expression, 'he assaulted me' (lines 36-7) categorises the caller as the victim of her expartner's violence and the description 'I put him in jail' (line 37) makes clear that the expartner is imprisoned because of his violence against her. In contrast, understanding the same things from the ex-partner being 'still in custody' (line 2) relies on members' reasoning based on social knowledge.

In the extract below, like the one above, the caller is seeking information regarding the possible location of someone she refers to as her 'ex-partner' (line 3). Our analysis shows the operation of the same common-sense reasoning practices as in the previous case.

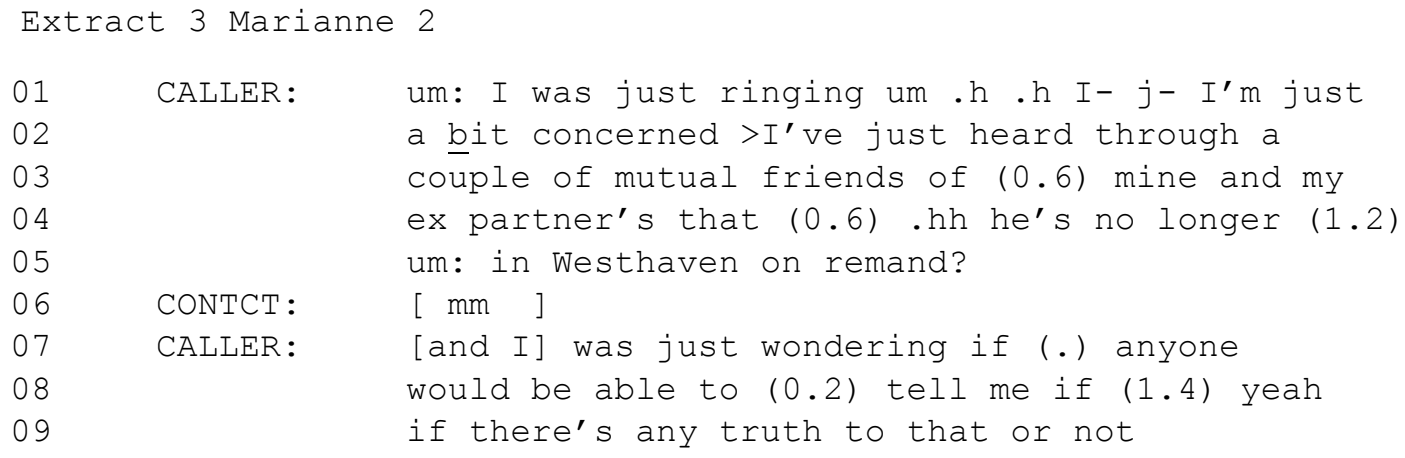

Being 'in Westhaven on remand' (line 5$)^{1}$ is a location associated with the identity of 'perpetrator'. The caller is understood as being a victim because it is paired to the category of perpetrator. The understanding that the ex-partner is in prison for assaulting her (rather than for some other crime) is available because, as explained above, crime is a duplicatively organised device where they are heard as belonging together. The membership categorisation device that most economically brings perpetrator-victim together with former couples is domestic or intimate partner violence.

In the call below, the caller requests help for making an 'oral submission to the parole board' (lines 4-5). The reference to that activity is sufficient for the call-taker to infer family violence as shown by the request for clarification (lines 48-50).

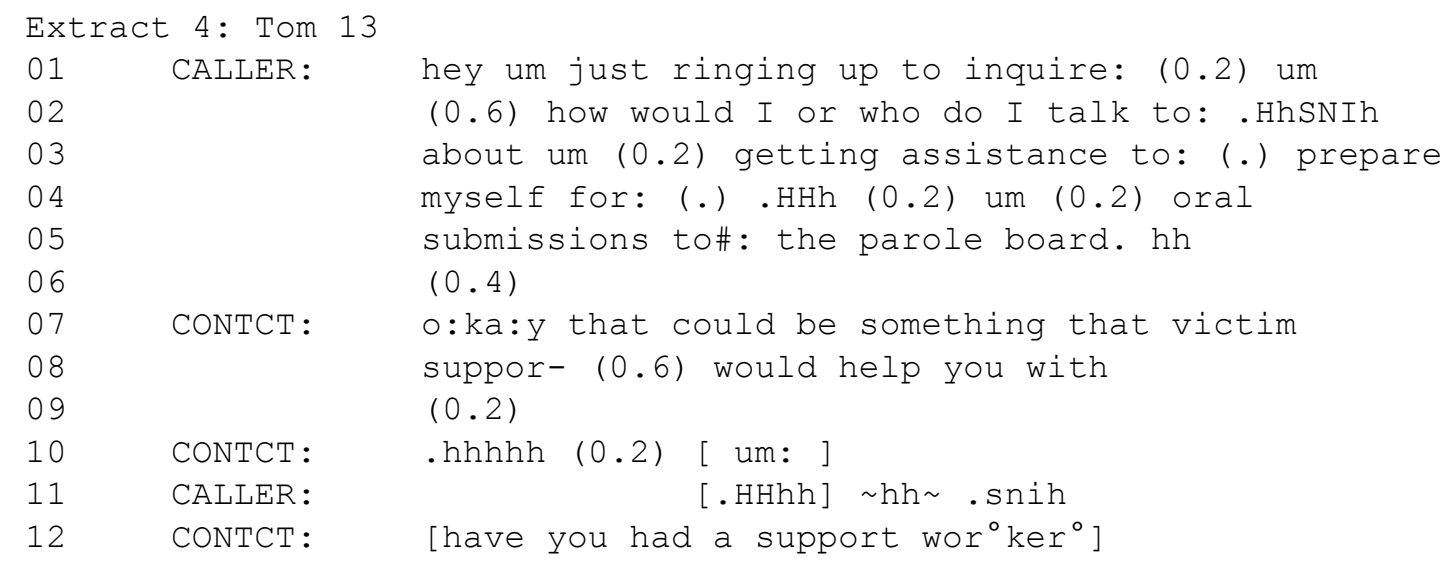

\footnotetext{
${ }^{1}$ Westhaven is a pseudonym for a correctional facility in a large New Zealand city.
} 


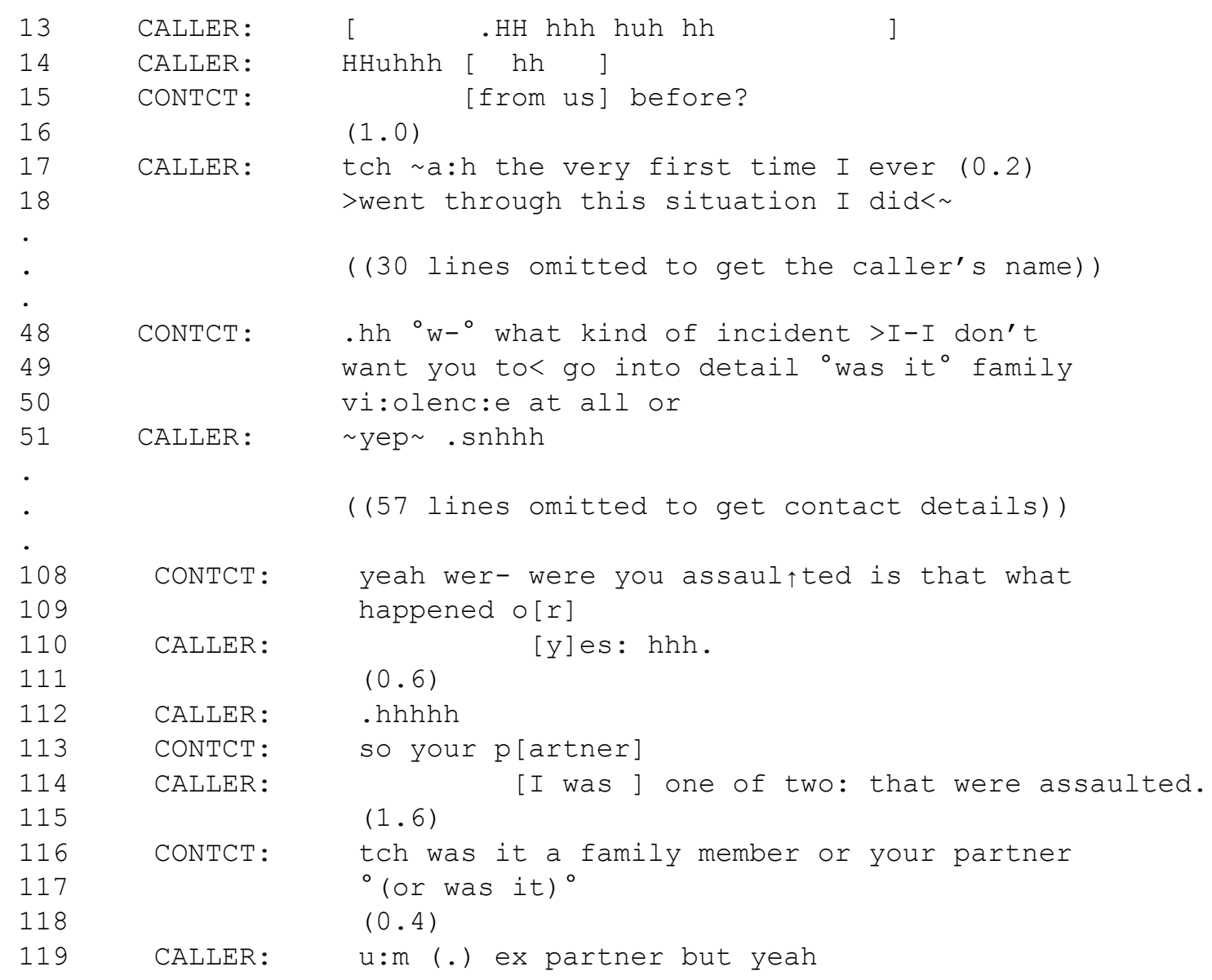

Anyone can make oral submissions about convicted perpetrators of crime when they have parole hearings. However, a category of caller that also is one of the kinds of people who can give oral submissions to a parole board is 'victim'. As analysts, there is nothing about a victim giving oral submissions that infers the crime domestic violence. Nevertheless, the calltaker does make that inference, requesting clarification of the relevant crime as family violence (lines 49-50). As it happens, the call-taker's common-sense is correct and the caller confirms it was family violence.

After getting the caller's address, the call-taker continues with further requests for clarification about details of what happened. Those requests also show the kinds of commonsense understandings of family violence as involving assault (line 108) by an intimate partner (line 113) or other family member (line 116). The caller confirms the call-taker's assumptions, with a correction of the category membership of the perpetrator as 'ex partner' (line 119).

The above example shows the largest common-sense inferential leap made in our collection of cases, which was from a reference to wanting help with making oral submission, to the inference of the crime as domestic violence against the caller. More accessible analytically, using the concept of membership categorisation devices, is that references to people as expartners and to the location of jail are linked in common-sense to domestic violence. Next, we show how similar reasoning practices operate with a different location, home. 


\section{The home}

Common-sense understandings of home are that home is a place of refuge (Wardhaugh 2012) and a site for familial relationships (Longhurst 2012). In the extract below, a caller describes 'problems at home' (line 3). Our analysis shows how that description makes available the inference that the caller is a victim of domestic violence perpetrated by her husband.

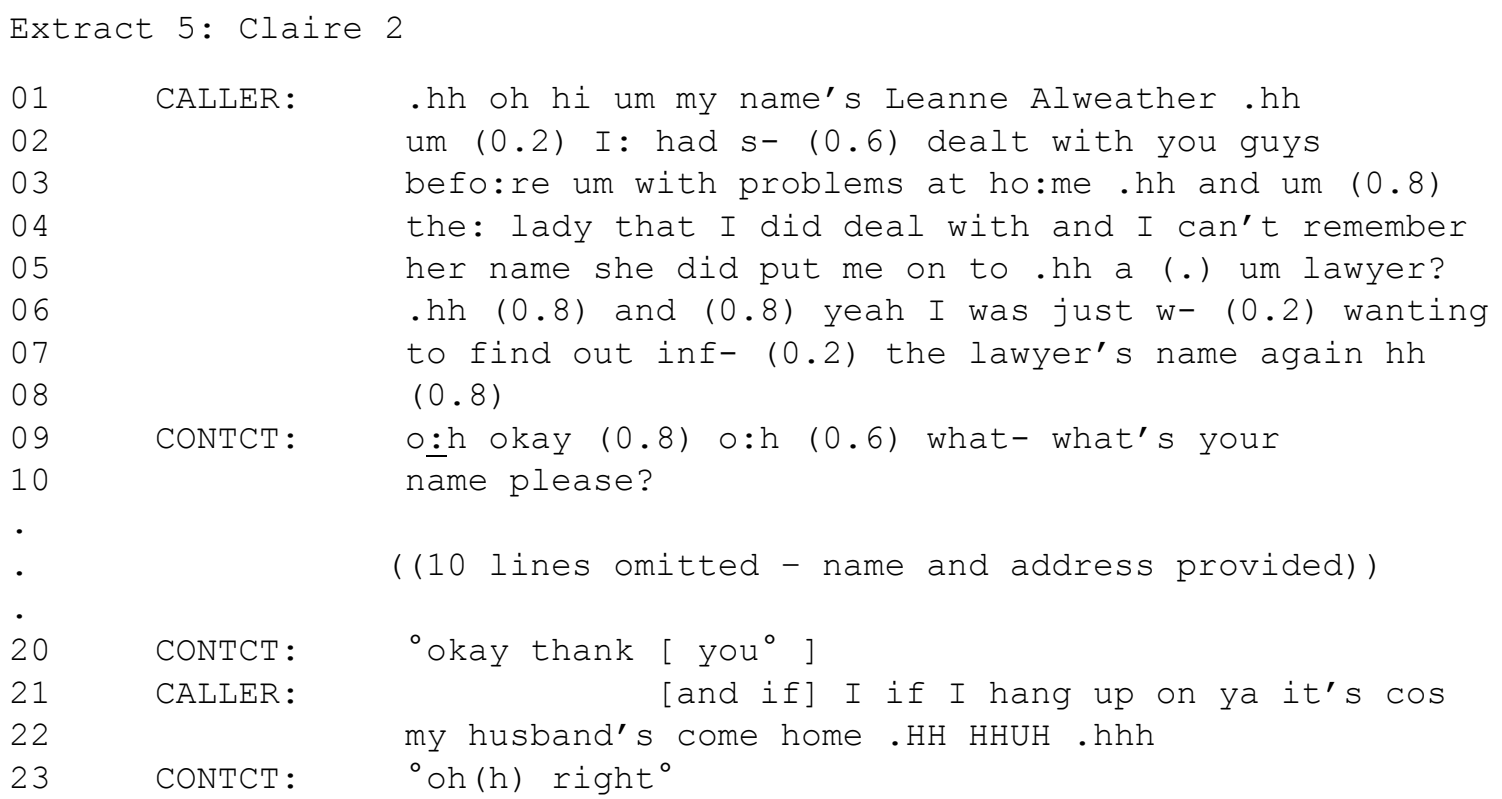

The caller can be categorised as a victim when she describes her prior dealings with the organisation. The category victim invokes its pair, perpetrator. The economy rule outlined above describes the way members of categories are heard as going together. In this case, the description 'problems at home' (line 3) most economically locates the two as living together. People who share a home are normatively understood as a couple. There can be various kinds of trouble at home, for example parenting or financial difficulties, but neither would warrant calling Victim Support. When victim and perpetrator live together, and the site of the problems is 'home', domestic violence can be inferred as a kind of trouble that does warrant seeking help from Victim Support.

The location of home is a place 'where one belongs, whose presence there is not accountable' (Schegloff 1972:98). Yet the caller describes her husband's return home as a consequential matter that would result in the unilateral termination of the phone call (lines 21-2). That description further strengthens the inference that the husband is the perpetrator, by qualifying the category 'husband' into 'abusive husband' (see Cuff 1993).

These common-sense reasoning practices and inferences are validated in the extract below. At a later point in the call, the caller describes her location as 'a marital home' (line 118) to re-specify the nature of her problem.

Extract $5 a$ Claire 2 


$\begin{array}{lll}114 & \text { CONTCT: } & \text { did you want to speak police again? } \\ 115 & (1.0) & \text {.hh no I won't right now, um (1.0) but he } \\ 116 & \text { CALLER: } & (0.4) \text { thin- well he's told me he's }(0.6) \text { um }(0.6) \\ 117 & \text {.hh because w- (0.2) this is a marital home .hh um } \\ 118 & \text { and obviously you know a-if we break up well he } \\ 119 & \text { wants me and my son out.hh um (0.4) so he's now s- } \\ 120 & \text { (.) sorta threatened me with lawyers and stuff } \\ 121 & \text { like that so.hhh j just wanted to know if there } \\ 122 & \text { was (0.6) w-the lady I spoke to the last time she } \\ 123 & \text { said there was a lawyer that you can go through } \\ 124 & \text { when you go through victim support }\end{array}$

Formulating her location as 'a marital home' (line 118) invokes the device marriage. Within this device, husbands and wives have common-sense rights of co-residence and shared property ownership. The caller indexes this shared cultural knowledge through 'obviously' and 'you know' (line 119; see Stokoe 2012b). The taken-for-granted upshot of a break-up is that her husband would want her and her son 'out' (line 119).

Naming someone as 'my son' (line 120) invokes the caller's identity as a mother. Breaking up is a possible response to violence, but for this caller and for other women in similar situations, this is not a simple matter. Categories of 'good mother' and 'victim of domestic violence' can lead to contradictory expectations (Ingrids 2014). For example, 'good victims' should leave violent relationships, but 'good mothers' should provide shelter and protection for their children. In New Zealand, conflicting responses to domestic violence, child protection, and family law mean that 'a mother may simultaneously be constructed as being responsible for protecting her children from the influence of an ex-partner's violence, in need of support and protection herself, and responsible for facilitating the other parent's contact with children' (Powell and Murray 2008:467).

The case below provides a counterpoint to the extracts above. Although the caller's description invokes the same common-sense links between relationships and home as Extract 5 above, the contact service worker does not understand this as a disclosure of domestic violence.

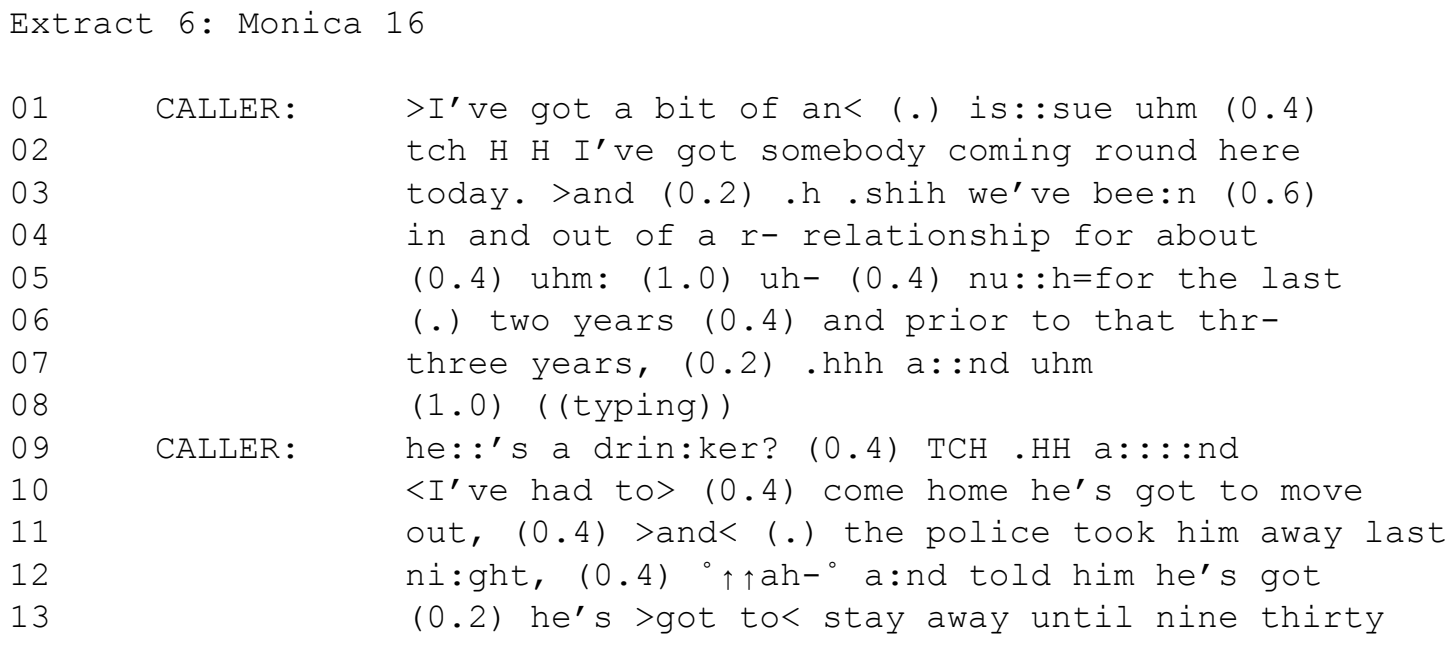


51

(0.4) this morning?

((31 lines omitted - further description))

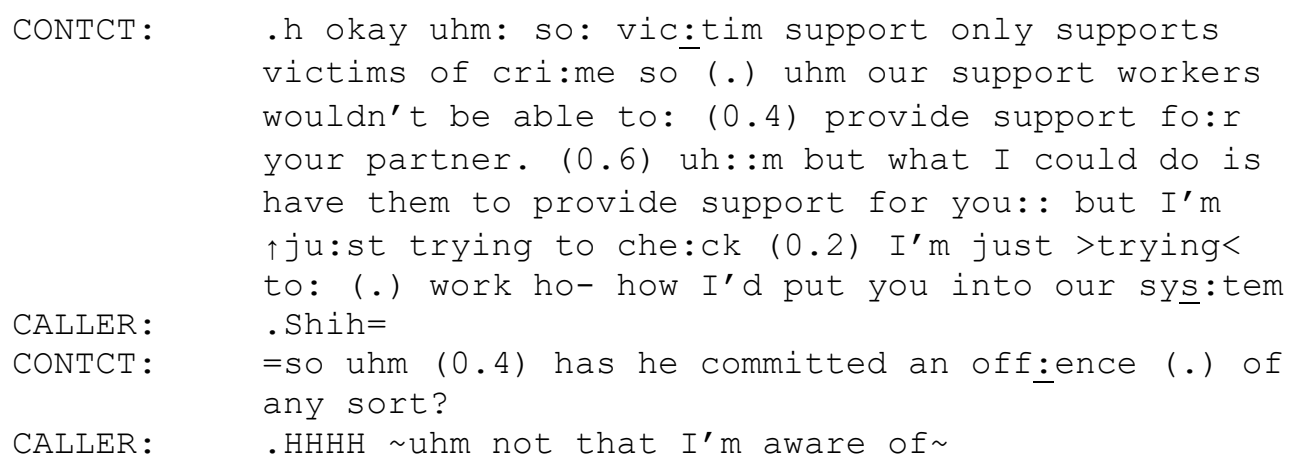

The caller begins her description with the announcement, 'I've got somebody coming around' (line 2) which is a rather idiomatic expression for the ordinary activity of having a visitor. The location 'here' (line 2) can be understood as referring to the caller's home through the mundane activity of having visitors that happens at a place of residence. The reference to 'somebody' (line 2) provides limited information about the person and suggests an association of little consequence. The nature of the caller's problem becomes more transparent when she further describes who the somebody is - a person with whom she has been 'in and out of a r-relationship' (lines 3-4) for a number of years. That description makes the identity of an (ex) partner inferentially available. The caller goes on to categorise him as 'a drinker' (line 8). That label is associated with people who have problems with alcohol, which is often implicated in abusive and violent behaviour. A further allusion to violence is police involvement and what is likely a description of a police safety order (lines 13-16), which can be issued when family violence has occurred and the victim is believed to be at risk. A safety order binds the perpetrator to stay away from home for a specified amount of time.

However, in contrast to the cases above, this description (and the common-sense associated with the categories of person and place reference) is not understood by the contact service worker as a disclosure of violence. When the caller requests a support person to be present when her partner arrives (not shown in the transcript), the contact service worker describes the service (lines 47-51) in a way which displays her understanding that the caller is seeking help for her partner. The contact service worker's contingent offer to support the caller herself (lines 53-57) displays that she has not yet understood the caller as someone legitimately entitled to the service. The question, 'has he committed an offence? of any sort!' (lines 59-60) and the caller's denial (line 61) display both participants' understanding that the caller's experiences cannot be categorised as a crime (see Tennent in press).

Although the contact service worker does later manage to enter the caller into the database (by categorising the incident as a verbal dispute), the extract above demonstrates how understanding the caller as a victim of violence is a joint accomplishment. Although in some cases such an understanding can be achieved through minimal reference and category terms 
(e.g. Extract 4), in other cases, much more interactional work is needed for callers to be understood as legitimate clients of the service.

We have shown the different ways joint understanding of domestic violence is achieved, ranging from callers' direct references to violence, to person and place references that invoke common-sense inferences about violence. The location of 'jail' invoked the membership categorisation device crime, while the location 'home' invoked common-sense associations of shared family residence. These place references, in combination with relationship categories, allowed the understanding of a familial relationship context for the violence, and situated this in the domestic location of home. In some cases, these categories and inferences were sufficient to understand the caller as a victim of violence, while in others relying on categorical inferences posed additional difficulties to getting help.

\section{Discussion}

We have shown that disclosures of violence even when calling a Victim Support helpline tend to be implicit. Only a minority of callers made direct reference to violence. When it did occur, descriptions of the incident or self-categorisation as a victim tended to occur in the opening of the call, regularly in callers' first turn of talk. The early disclosure should not be taken as evidence that these disclosures were straightforward or easy. Instead, detailed analysis showed troubles with formulating experiences of violence - even to a helpline for victims. Features of production such as perturbations or trouble in word selection can be used as interactional evidence of the challenges associated with disclosure that has also been documented in other work (see Othman, Goddard and Piterman 2014). Furthermore, the words used to describe the violence were drawn from an institutional register, which may gloss over the complexity of the ongoing challenges for women who have suffered violence.

Rather than making direct reference to violence, the majority of callers built their disclosures by invoking categories of people (e.g. husband, expartner) and places (e.g. home, jail). Our analysis showed that a description of an ex-partner in jail produced the inference of violence within a Disclosing violence in calls for help 285 previous relationship, for which the perpetrator is now imprisoned. Similarly, linking the activity of hanging up the phone when a husband returns home produced an inference of violence within a current relationship in the family home. Although not an aim of the research, the link between expartners and jail brought to the fore the ongoing problems women face even after reporting violence, ending a relationship, and achieving conviction and imprisonment within the criminal justice system. Our data provides grounded evidence that even after perpetrators are imprisoned, women are still negatively impacted from the ongoing possibility of violence.

Our findings complement and broaden existing studies on disclosures of violence. Interview research has identified a number of challenges associated with disclosure by asking women about their experiences (Othman, Goddard and Piterman 2014; Keeling and Fisher 2015). In contrast, our work analyses how disclosures are produced in social interaction. To fully understand disclosures, it is important to study the way they are done in situ. Our analysis 
demonstrated how women's disclosures were used to establish themselves as legitimate clients of the service in order to get help. However, disclosures in different settings can be used for different interactional purposes. As mentioned in the introduction, MacLeod (2016) found that women frequently accounted for their behaviour, orienting to rape myths and victim blaming when disclosing violence to police. There are comparatively few accounts in our data. Where they regularly occurred was in the opening of the interaction when the reason for calling was given. Later in the call they could occur to explain why a proposed course of action was being rejected. A key reason for our different findings is the nature of the institutional business participants are involved in. Rather than reporting a crime, as in MacLeod's data, callers in our sample disclose experience of violence in order to access the service of emotional support.

Although disclosures of violence are a relevant activity when seeking help from Victim Support, the way contact service workers responded was constrained by their institutional roles. Contact service workers are not trained to provide emotional support in the here and now of the call but instead provide a conduit role of connecting callers to support workers. The organisation provides emotional support, but the phone calls we analysed were not the primary place where the support was provided. Thus, contact service workers largely responded to disclosures of violence minimally or progressed a relevant activity such as gathering details, or offering service, rather than providing emotional support through affiliative responses or giving advice.

As part of our ongoing research, we intend to develop evidence-based training from the research findings. We aim to give contact service workers a greater understanding of the different ways callers present their problems when seeking support, and the best ways to manage the interactional dilemmas that arise. By helping Victim Support be more responsive to victims of domestic violence, we can contribute to the broader feminist project of improving services for women, especially those who have experienced violence.

In conclusion, much research on women's disclosures treats disclosures as a taken-forgranted action. Yet by examining the different ways women build disclosures - from direct references to descriptions and categorisations - we have provided a grounded analysis of how disclosures actually occur in social interaction. This provides a unique contribution to the study of gender and language by examining the interactional context within which disclosures are produced, and how they are used to a particular end of seeking support after an experience of violence 


\section{References}

Bender, A. K. (2017). Ethics, Methods, and Measures in Intimate Partner Violence Research: The Current State of the Field. Violence Against Women, 23(11), 1382-1413. DOI: $10.1177 / 1077801216658977$

Cuff, E. C. (1993). Problems of Versions in Everyday Situations. Washington, D.C.: International Institute for Ethnomethodology and Conversation Analysis \& University Press of America.

Devries, K. M., Mak, J. Y. T., García-Moreno, C., Petzold, M., Child, J. C., Falder, G., . . . Watts, C. H. (2013). The Global Prevalence of Intimate Partner Violence Against Women. Science, 340(6140), 1527-1528. DOI:10.1126/science.1240937

Ehrlich, S (2001). Representing rape: Language and sexual consent. London: Routledge. Ehrlich, S. (2014). Language, Gender, and Sexual Violence. In S. Ehrlich, M. Meyerhoff \& J. Holmes (Eds.), The Handbook of Language, Gender, and Sexuality (pp. 452-470). Chichester, UK: Wiley Blackwell.

Fanslow, J., L., \& Robinson, E., M. (2011). Sticks, Stones, or Words? Counting the Prevalence of Different Types of Intimiate Partner Violence Reported by New Zealand Women. Journal of Aggression, Maltreatment \& Trauma, 20(7), 741-759. DOI: 10.1080/10926771.2011.608221

Fitzgerald, R., \& Housley, W. (Eds.). (2015). Advances in membership categorisation analysis. London, UK: SAGE Publications Ltd.

Gavey, N. (2005). Just Sex? : The Cultural Scaffolding of Rape. New York: Psychology Press.

Greatbatch, D., \& Dingwall, R. (1999). The marginalization of domestic violence in divorce mediation. International Journal of Law, Policy and the Family, 13(2), 174-190. DOI:10.1093/lawfam/13.2.174

Hepburn, A. (2004). Crying: Notes on Description, Transcription, and Interaction. Research on Language and Social Interaction, 37(3), 251-290. DOI:10.1207/s15327973rlsi3703_1

Hester, S. \& Eglin, P. (1997). Culture in action: studies in membership categorization analysis. Washington, D.C.: International Institute for Ethnomethodology and Conversation Analysis \& University Press of America

Ingrids, H. (2014). Category work in courtroom talk about domestic violence: Gender as an interactional accomplishment in child custody disputes. Feminism \& Psychology, 24(1), 115-135. DOI:10.1177/0959353513515294

Jefferson, G. (2004). Glossary of transcript symbols with an introduction. In G. Lerner, H. (Ed.), Conversation Analysis. Studies from the first generation (pp. 13-31). Philadelphia: USA: John Benjamins Publishing Company.

Jordan, J. (2004). Beyond belief? Police, rape and women's credibility. Criminal justice, 4(1), 29-60. DOI: $10.1177 / 1466802504042222$ 
Jordan, J. (2011). Here we go round the review-go-round: Rape investigation and prosecution - are things getting worse not better? Journal of Sexual Aggression, 17(3), 234-249. DOI:10.1080/13552600.2011.613278

Jordan, J. (2015). The long and winding road: Improving police responses to women's rape allegations. Critical issues on violence against women: International perspectives and promising strategies. (pp. 104-116): Routledge, New York, NY.

Keeling, J., \& Fisher, C. (2015). Health Professionals' Responses to Women's Disclosure of Domestic Violence. Journal of Interpersonal Violence, 30(13), 2363-2378.

DOI:10.1177/0886260514552449

Lamb, S. (1999). Constructing the Victim. Popular images and lasting lables. In S. Lamb (Ed.), New versions of victims : feminists struggle with the concept (pp. 108-138). New York: New York University Press.

Lees, S. (2002). Carnal knowledge: rape on trial. London: Women's Press.

Lindholm, J., Börjesson, M., \& Cederborg, A.-C. (2014). 'What happened when you came to Sweden?' Attributing responsibility in police interviews with alleged adolescent human trafficking victims. Narrative Inquiry, 24(2), 181-199.

DOI:10.1075/ni.24.2.01lin

Lombard, N., \& McMillan, L. 2013. Violence against women: Current theory and practice in domestic abuse, sexual violence, and exploitation. London, UK: Jessica Kingsley Publishers.

Longhurst, R. (2012). Feminist Perspectives on Home. International Encyclopedia of Housing and Home (pp. 158-162). San Diego: Elsevier. DOI: 10.1016/B978-0-08047163-1.00319-2

MacLeod, N. (2016). "I thought I'd be safe there": Pre-empting blame in the talk of women reporting rape. Journal of Pragmatics, 96, 96-109.DOI:10.1016/j.pragma.2016.03.008

Ostermann, A. C. (2003). Communities of Practice at Work: Gender, Facework and the Power of Habitus at an All-Female Police Station and a Feminist Crisis Intervention Center in Brazil. Discourse \& Society, 14(4), 473-505.

DOI:DOI:10.1177/0957926503014004004

Othman, S., Goddard, C., \& Piterman, L. (2014). Victims' Barriers to Discussing Domestic Violence in Clinical Consultations:A Qualitative Enquiry. Journal of Interpersonal Violence, 29(8), 1497-1513. DOI:10.1177/0886260513507136

Powell, A., \& Murray, S. (2008). Children and Domestic Violence: Constructing a Policy Problem in Australia and New Zealand. Social \& Legal Studies, 17(4), 453-473. DOI: $10.1177 / 0964663908097080$

Sacks, H. (1972). On the Analyzability of Stories by Children. In J. J. Gumperz \& D. Hymes (Eds.), Directions in Sociolinguistics: The Ethnography of Communication (pp. 325345). New York, NY: Holt, Rinehart and Winston, Inc.

Sacks, H. (1995). Lectures on conversation (G. Jefferson Ed.). Oxford, UK: Blackwell. Schegloff, E., A. (1972). Notes on a Conversational Practice: Formulating Place. In D. N. Sudnow (Ed.), Studies in Social Interaction (pp. 75-119). New York: MacMillan. Schegloff, E., A. (2007). A tutorial on membership categorisation. Journal of Pragmatics, 39(3), 462-482. DOI:10.1016/j.pragma.2006.07.007 
Schegloff, E., A. (2010). Some other "uh(m)"s. Discourse Processes, 47(2), 130-174. DOI: $10.1080 / 01638530903223380$

Schegloff, E., A., Jefferson, G., \& Sacks, H. (1977). The Preference for Self-Correction in the Organization of Repair in Conversation. Language, 53(2), 361-382. DOI: $10.2307 / 413107$

Stokoe, E. (2012a). Moving forward with membership categorization analysis: Methods for systematic analysis. Discourse Studies, 14(3), 277-303.

DOI: $10.1177 / 1461445612441534$

Stokoe, E. (2012b). "You know how men are": Description, categorization and common knowledge in the anatomy of a categorial practice. Gender and Language, 6(1), 233255. DOI: $10.1558 /$ genl.v6i1.233

Stokoe, E. H. (2003). Mothers, Single Women and Sluts: Gender, Morality and Membership Categorization in Neighbour Disputes. Feminism \& Psychology, 13(3), 317-344. DOI:10.1177/0959353503013003006

Towns, A. \& Adams, P. (2009). Staying quiet or getting out: some ideological dilemmas faced by women who experience violence from male partners. British Journal of Social Psychology, 48(4) 735-754. DOI: 10.1348/014466608X398762

Wardhaugh, J. (2012). Feminist Perspectives on Homelessness. International Encyclopedia of Housing and Home (pp. 163-171). San Diego: Elsevier.

Wowk, M. T. (1984). Blame allocation, sex and gender in a murder interrogation. Women's Studies International Forum, 7(1), 75-82. DOI:10.1016/0277-5395(84)90087-6 